1987-01-01

\title{
Anneal Induced Changes in Amorphous Semiconductor Multilayers
}

\author{
David D. Allred \\ allred@byu.edu \\ Jesus González-Hernández \\ O. V. Nguyen
}

Follow this and additional works at: https://scholarsarchive.byu.edu/facpub

Part of the Astrophysics and Astronomy Commons, and the Physics Commons

\section{Original Publication Citation}

J. González-Hernández, David D. Allred, and O.V. Nguyen, "Anneal Induced Changes in Amorphous Semiconductor Multilayers," Interfaces, Superlattices and Thin Films, Materials Research Society Symposium Proceedings, 77, 665-67, (1987). [http://journals.cambridge.org/action/

displayAbstract?fromPage=online\&aid=8168785\&fulltextType=RA\&fileld=S19464274513682][http://dx.doi.org/ 1.1557/PROC-77-569].

\section{BYU ScholarsArchive Citation}

Allred, David D.; González-Hernández, Jesus; and Nguyen, O. V., "Anneal Induced Changes in Amorphous Semiconductor Multilayers" (1987). Faculty Publications. 1202.

https://scholarsarchive.byu.edu/facpub/1202

This Peer-Reviewed Article is brought to you for free and open access by BYU ScholarsArchive. It has been accepted for inclusion in Faculty Publications by an authorized administrator of BYU ScholarsArchive. For more information, please contact ellen_amatangelo@byu.edu. 


\section{ANNEAL INDUCED CHANGES IN AMORPHOUS SEMICONDUCTOR MULT ILAYERS}

J. Gonzalez-Hernandez*, D.D. Allred** and 0.V. Nguyen

*CINVESTAV-IPN, Depto. de Fisica, Ap. Postal 14-740, Mexico, D.F.

**Energy Conversion Devices, Inc., 1675 West Maple Road, Troy, Michigan 48084

\section{ABSTRACT}

We have prepared, heat treated and characterized various amorphous semiconductor periodic multilayers and ultrathin films. These were prepared by several vapor deposition techniques at substrate temperatures ranging from $25^{\circ} \mathrm{C}$ to $300^{\circ} \mathrm{C}$ and possessed periodicities from 22 to $400 \AA$. Films were subjected to isochronal thermal treatments at progressively higher temperatures. Two effects were observed: enhanced diffusion and retarded crystallization. Interdiffusion, at rates which are many orders of magnitude higher than those anticipated from crystalline data, was observed in a-Si/a-Ge multilayers. Crystallization of germanium, the more readily crystallized member of the couple, is retarded; the extent depends on the thickness of the layer. The thinner the layer, the greater the retardation. Where intermixing is thermodynamically unfavorable as in a-Si/a-SiN $x$ or a-Ge/a-SiN multilayers, and ultrathin germanium layers on $\mathrm{SiO}_{2}$, interdiffusion does not occur, however, crystallization of silicon or germanium is again substantially retarded.

\section{INTRODUCTION}

There has been a dramatic increase in the study and development of artificially structured materials during the past decade. Recently, a great deal of interest has been centered on the fabrication of ultrathin films and multilayers using amorphous semiconductors $[1,2]$. For these applications, thermal stability is an important factor for ensuring device performance. Although there have been many studies of the thermal stability of metal/metal $[3,4]$ and metal/semiconductor $[5,6]$ multilayer films, relatively little is known about the thermal properties of amorphous semj.conductor/amorphous semiconductor and amorphous semiconductor/dielectric $[7,8]$ multilayer films.

To understand the temperature induced structural changes in amorphous multilayers, a series of a-Si/a-Ge, a-Si/a-Si:N $\mathrm{N}_{x}$ and a-Ge/a-Si:N periodic bilayers were prepared by several techniques and characterized us ing Raman spectroscopy (RS) and low angle $x$-ray diffraction (LAXRD). We have observed two notable effects: $i$ ) retardation of crystallization of ultrathin films and multilayers of small periodicity and, ii) diffusion at rates orders of magnitude higher than expected from crystalline data. These novel effects appear to be negligible for films $200 \AA$ or thicker. In this paper, the terms "ultrathin" or "nanostructure" are used to refer specifically to materials in the less than approximately $200 \AA$ thickness range where such distinct properties are observed. Similarly, the term "thin film" is applied to films thicker than approximately $200 \AA$. Most prior studies of the annealing of tetrahedral semiconductors have been limited to the realm of thin films.

\section{EXPERIMENTAL-}

Regular, periodic amorphous multilayer structures were prepared by various vapor deposition techniques. A PHI-400 Molecular Beam Epitaxy (MBE) System was used for the preparation of the unhydrogenated a-Si/a-Ge samples. These were termed molecular beam deposited, MBD, multilayers. The nominal thickness of the silicon and the germanium layers in each period were equal. 
Further details on the preparation of the multilayers are found in Ref. [9, 10]. Multilayers consisting of alternating layers of a-Si or a-Ge and a-SiN were prepared by ion beam sputtering using a $2.5 \mathrm{~cm}$ Kaufman ion source operating with pure argon for germanium or silicon and with a mixture of argon and nitrogen for the preparation of the a-SiN layer [9]. a-Si:H/a-SiN ${ }_{x}: H$ multilayers were prepared by glow discharge [10]. Samples were annealed in argon in a furnace.

Both the $5145 \AA$ and $4880 \AA$ lines of an $\mathrm{Ar}^{+}$ion laser were employed in the Raman measurements. The LAXRD measurements were obtained using a Phillips XRD-2500 diffractometer equipped for $\mathrm{CrK}_{\alpha}$ and CuK ${ }_{\alpha}$ radiation.

\section{RESULTS AND DISCUSSION}

Atomic diffusion, in covalent amorphous semiconductor multilayers, has not been studied until very recently. Prokes and Spaepen [8] prepared non-hydrogenated a-Si/a-Ge inultilayers by ion beam sputtering and measured the interdiffusion coefficient, $D$, using $X$-ray diffraction techniques. From the Arrhenius plot, the value for the activation energy is $E_{a}=1.6 \mathrm{eV}$. More recently, Persans and Rupper [7], using RS, studied the diffusion process in a-Si:H/a-Ge:H multilayers prepared by plasma assisted chemical vapor deposition. By contrast, the activation energy of these hydrogenated multilayers is $2.3 \mathrm{eV}$. It was thought that this might indicate the rate limiting step was bond breaking, possibly related to hydrogen effusion.

To understand the role that deposition parameters play in the interdiffusion process, the MBE system was used to prepare a series of regular periodic a-Si/a-Ge multilayers at various substrate temperatures, $T_{s}$, over the range of room temperature to $300^{\circ} \mathrm{C}$.

In Figure 1, we show the Raman spectrum of a multilayer deposited at $\tau_{s} \simeq$ $25^{\circ} \mathrm{C}$ before and after a series of isochronal anneals $\left(t_{a}=60 \mathrm{~min}\right.$ ) at 400 , 550,600 and $700^{\circ} \mathrm{C}$. Several points can be inferred from this figure:

a. After heat treatment, the relative intensity of the Si-Ge local mode at $\sim 370 \mathrm{~cm}^{-1}$ increased with the increase of the annealing temperature, indicating that mixing at the interfaces was occurring.

b. Normally, buik a-Ge crystallized within a few minutes at $450^{\circ} \mathrm{C}$, but in these nanostructure multilayers crystallization was substantially retarded. More conclusive evidence of this retardation effect will be presented in the following paragraphs.

c. Crystallization occurred only after complete intermixing was achieved. Thus, the structure crystallized into a homogeneous alloy with a nearly equal $\mathrm{Si} / \mathrm{Ge}$ composition as determined by the position and relative intensities of the Raman peaks in Figure le.

The alloy width, $\omega$, was calculated following the method described in Ref. [10] for data summarized in Figure 1 and for intermediate temperatures. Values of $\omega=6,19,53$ and $100 \AA$ were obtained after isochronal ( $t_{a}=3600$ $\mathrm{sec}$ ) annealings at temperatures of $400,450,500$ and $550^{\circ} \mathrm{C}$ respectively. The temperature dependence of the diffusion coefficient, $D,\left(D=\omega / t_{a}\right)$ is plotted versus $1 / k T$ in Figure 2 (circled dots), $k$ being the Boltzman constant. From the slope and intercept, respectively, of the upper line, an activation energy of approximately $1.5 \mathrm{eV}$ was obtained.

Similarly, a (50\&/50 nominal) MBD a-Si/a-Ge multilayer prepared at $\mathrm{T}_{\mathrm{s}}=$ $300^{\circ} \mathrm{C}$ was annealed for $\mathrm{l} \mathrm{hr}$ at the same temperatures. The calculated alloy 
widths after $400,450,500$ and $550^{\circ} \mathrm{C}$ heat treatment, were $\omega=1,2.5,4.5$ and $9 \AA$ respectively, although the extent of interdiffusion is less; an activation energy $\left(E_{a}=1.4 \mathrm{eV}\right)$, comparable to samples at $T_{s}=R T$, was calculated.

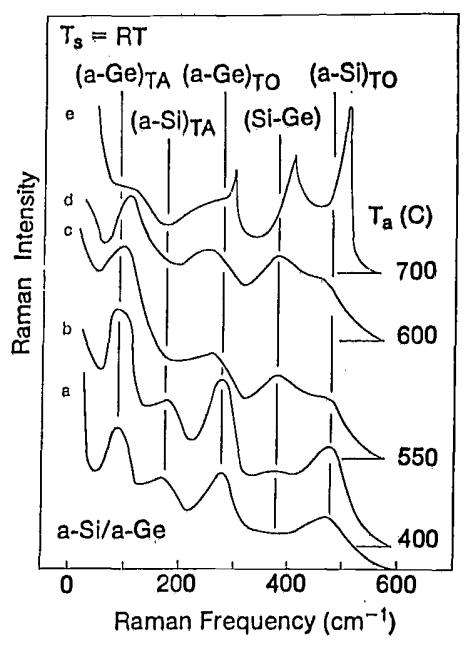

Fig. I Raman spectra of a MBD a-Si/a-Ge multilayer annealed at different temperatures.

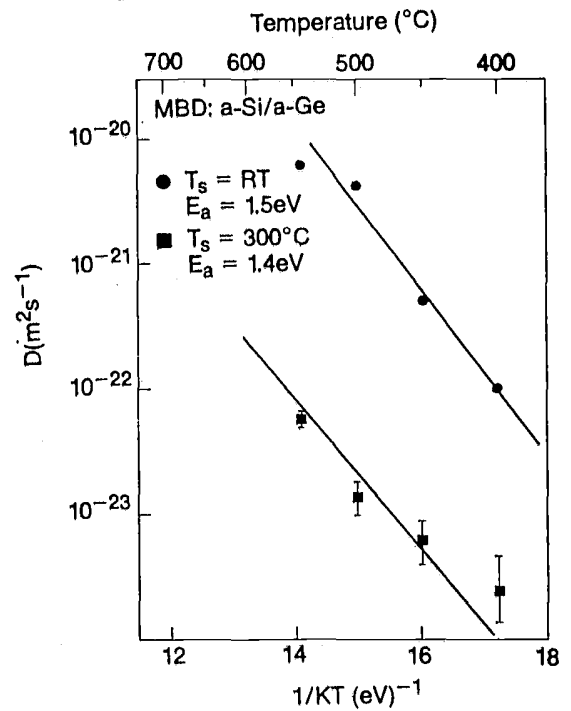

Fig, 2 Arrhenius plot for MBD a-Si/a-Ge multilayers prepared at $\mathrm{T}_{\mathrm{S}}=\mathrm{RT}$ and $300^{\circ} \mathrm{C}$.

The observed decrease in diffusion rate, in the multilayers between $T_{s}=25$ and $300^{\circ} \mathrm{C}$, correlates qualitatively with the known decrease in defect density of a-Si and a-Ge thin films, as $T_{s}$ increases over the same temperature range. Since diffusion can be tied to defect density and structure on an atomic level, the observed decrease in diffusion rate with increasing temperatures suggests the defect density of the multilayers which similarly declines as $T_{\text {s }}$ increases.

The diffusion rates of amorphous silicon and germanium in these multilayers are many orders of magnitude higher than those measured for their crystalline counterparts. This has previously been observed for samples prepared by other techniques [7,8]. From Figure 2, $D\left(400^{\circ} \mathrm{C}\right) \simeq 10^{-22} \mathrm{~m}^{2} \mathrm{~s}^{-1}$, whereas diffusivities at the same temperature for Ge in crystalline silicon and in crystalline germanium have been extrapolated to be only $4.35 \times 10^{-37} \mathrm{~m}^{2} \mathrm{~s}^{-1}$ [11] and $5.3 \times 10^{-30} \mathrm{~m}^{2} \mathrm{~s}^{-1}$ [12] respectively.

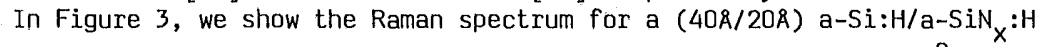
periodic multilayer before and after anneal at $400,500,700$ and $850^{\circ} \mathrm{C}$. The Raman spectrum of the a-Si:N $x: H$ layer had no distinctive features because of its much lower-Raman cross-section, and hence did not contribute to Figure 3.

Changes in the Raman spectrum, of thin film a-Si after heat treatments, have been reported [13].

The changes in the frequency and relative intensity of the main two features in the Raman spectrum induced by low annealing temperature $\left(\mathrm{T}_{\mathrm{a}} \sim 400^{\circ} \mathrm{C}\right)$ were related to hydrogen effusion while higher anneal,ing temperatures induced changes were associated with an improvement in the microscopic structural order [13]. In contrast, the Raman spectra of the 


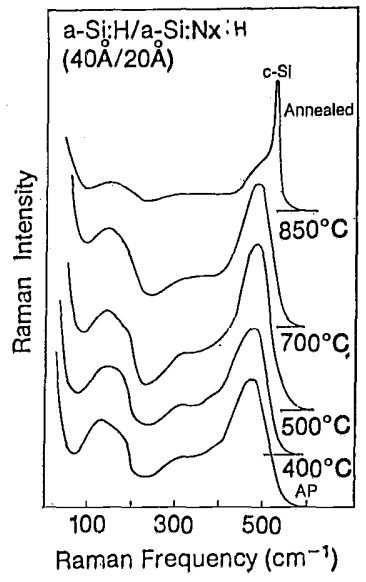

Fig. 3 Raman spectra of an a-Si:H/ a-Si:H:N $N_{x}$ multilayer before and after annealed.
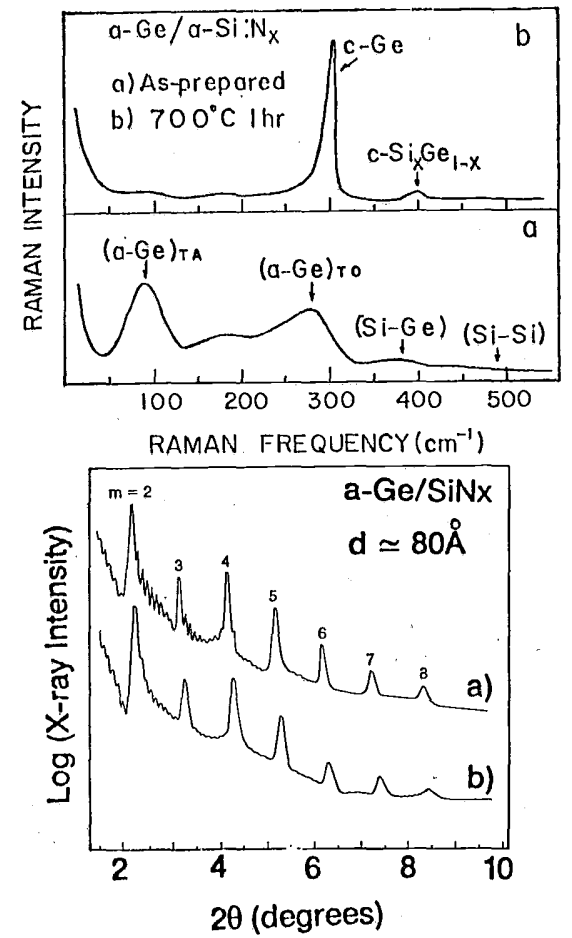

Fig. 4 Raman spectra (top) and LAXRD (bottom), as-prepared and annealed at $700^{\circ} \mathrm{C}$ a-Ge/a-SiN $x$ multilayer. multilayers annealed in this study were observed not to have changed after having been subjected to thermal treatments which would substantially alter the spectra of thin film a-Si:H. Neither a frequency shift nor a change in the amplitude of the main Raman peaks were observed after an anneal at temperatures below the crystallization temperature. The thermal stability of the Raman signal implies negligible structural changes on the atomic level at a microscopic scale in the a-Si:H phase. This is further reflected in a decreased tendency toward thermally induced crystallization. Whereas a-Si and a-Si:H thin films $>200 \AA$ thick crystallized in one hour at $\mathrm{T}_{\mathrm{a}} \sim 700^{\circ} \mathrm{C}$, it was found that the crystallization temperature, $T_{c}(1 \mathrm{hr})$, of ultrathin a-Si:H layers in multilayer structures was elevated.

The thinner the a-Si:H layer, the higher was $T_{C}(l \mathrm{hr})$. For instance, for the a-Si:H layers in a $40 \AA$ a-Si:H/ $20 \AA$ a-SiN $x: H$ multilayer $T_{C}(l \mathrm{hr})=850^{\circ} \mathrm{C}$ while for the $20 \AA$ a-Si:H/40A a-Si: $N_{X}: H$ multilayer, $T_{C}(I, h r)=1000^{\circ} \mathrm{C}$. It should be noted that based on both LAXRD and RS data no measurable thermal induced layer intermixing occurred.

A similar retardation effect was observed in a-Ge/a-Si: $N_{x}$ multilayers prepared by ion beam sputtering. In this system, as in the a-Si:H/a-SiN $\mathrm{X}: H$ case, interdiffusion is energetically unfavorable. The germanium layers crystallized at annealing temperatures much higher than those observed for thicker layers ( $\sim 200 \AA)$.

In Figure 4, we show Raman (top) and LAXRD (bottom) data for an a-Ge/a-Si:N $x$ multilayer film with a nominal structure of $50 \AA$ a-Ge/15 a-Si: $N_{x}$ as-prepared and after heating at $700^{\circ} \mathrm{C} / \mathrm{l} \mathrm{hr}$. After successive exposures to increasing temperatures, the a-Ge layer crystallizes at $\mathrm{T}_{\mathrm{a}}=$ $700^{\circ} \mathrm{C} / \mathrm{l} \mathrm{hr}$. as indicated by the sharp crystalline germanium (c-Ge) peak at $297 \mathrm{~cm}^{-1}$. The Si-Ge peak in the range of $390 \mathrm{~cm}^{-1}$ remains weak, providing evidence that there is little inter- 


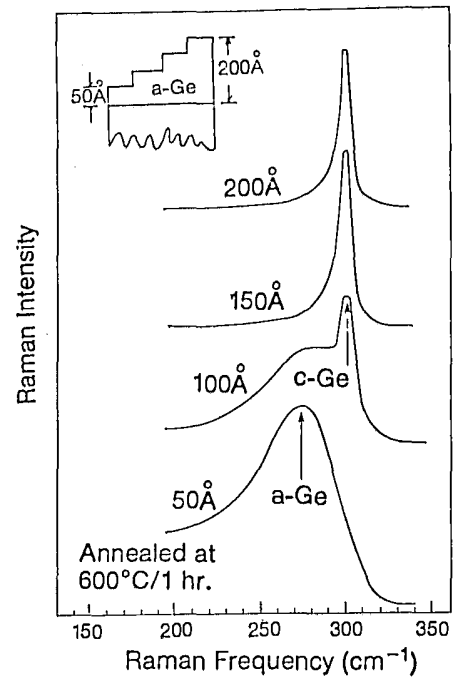

Fig. 5 Raman spectra of MBD a-Ge ultrathin film having various thicknesses after annealed at $600^{\circ} \mathrm{C}$. the crystallization tenperature for a d the crystallization temperature for a crystallization occurs only for the annealing temperatures promotes crystallization of progressively thirner germanium layers. At $\mathrm{T}_{\mathrm{a}}=600^{\circ} \mathrm{C}$ (Figure 5), with the exception of the $50 \AA$ thick region, all the remaining regions are totally or partially (100 $\AA$ ) crystalline.

While thickness has been cited previously as one of many parameters (including purity substrate and environment) which influence the crystallization kinetics of a-Si and a-Ge [15], until this investigation of nanostructures, the effect of thickness on crystallization temperature was found to be relatively modest. Our results show that a reduction of layer thickness to order of several nanometers results in a substantial thermal stabilization at the amorphous phase and retardation of crystallization.

A possible microscopic mechanism for thermal stability of ultrathin amorphous layers can be drawn from the analysis of Zellama et al. [16] on the crystallization of a-Si layers. Their results allow one to compute the approximate values of the thermodynamic parameters which characterize the crystallization. It was found that crystallization can only occur if spherical nucleation sites having a minimum critical size ( $15 \AA$ diameter) can be formed. Accordingly, amorphous layers with thickness comparable to the critical size are thermodynamically stable, even at annealing temperatures above the crystallization temperatures of thicker films.

\section{CONCLUSIONS}

Annealed induced changes in various types of amorphous periodic multilayers are reported. Samples showing very sharp interfaces (little evidence of layer intermixing) exhibit novel transformations including: 
a) interdiffusion at a rate orders of magnitude higher than anticipated from crystalline data; and b) retardation of crystallization in ultrathin amorphous layers and multilayers having small periodicities (nanostructure multilayers). It is suggested that the enhanced diffusion process, in the amorphous phase, proceeds via defects, i.e., possible dangling bonds.

\section{ACKNOWLEDGEMENT}

We wish to thank E.M. Norman, Marilyn St. John and M. Lipton for their assistance in the preparation of the manuscript.

\section{REFERENCES}

1. J. Kakalios, H. Fritzsche, N. Ibaraki and S.R. Ovshinsky, J. of Non-Cryst. Solids, 66, 339 (1984).

2. B. Abeles, T. Tiedje, K.S. Liang, H.W. Deckman, H.C. Stasilwski, J.C. Scanlon and P.M. Eisenberger, J. of Non-Cryst. Solids, 66, 351 (1984).

3. E. Ziegler, Y. Lepetre, I.K. Schuller and E. Spiller, Appl. Phys. Lett., 48, 1354 (1986).

4. D.M. Follstaedt and S.A. Knapp, Phys. Rev. Lett., 트, 1827 (1986).

5. Y. Takagi, S.A. Flessa, K.L. Hart, D.A. Pawlik, A.M. Kadin, J.L. Wood, J.E. Keem and J.E. Tyler, Proceed. SPIE, 563, 66 (1985).

6. M. Natan and S.C. Shatas, S. Vac. Sci. Technol., B3, 1707 (1985).

7. P.D. Persans and A.F. Ruppert TMS/MRS Northeast Regional Meeting, May, 1986, Murray Hill, NJ.

8. S.M. Prokes and F. Spaepen, Appl. Phys. Lett., 47, 234 (1985).

9. J. Gonzalez-Hernandez, D.D. Allred, O.V. Nguyen, D. Martin and D. Pawlik, Mat. Res. Soc. Symp., 56, 389 (1986).

10. D.D. Allred, J. Gonzales-Hernandez, O.V. Nguyen, D. Martin and D. Pawlik, J. Mat. Res., 1, 468 (1986).

11. W. Frank, U. Gosele, H. Mehrer and A. Seeger, in Diffusion in Crystalline Solids, Ed. by G.E. Murch and A.S. Nowick (Academic, New York, to be published).

12. A.M. Brown and M.F. Ashby, Acta Metall., 28, 1085 (1980).

13. R. Tsu, J. Gonzalez-Hernandez and.F.H. Pollak, J. of Non-Cryst. Solids, 66, 109 (1984).

14. J.H. Underwood and T.W. Barbee Jr., AIP Conf. Proc., No. 75 on Low Energy X-Ray Diagnostic, p. 170 (1981).

15. M.H. Brodsky, R.S. Title, K. Weiser and C.D. Petit, Phys. Rev. B, 1, 2632 (1970).

16. K. Zellama, P. Germain, S. Squelard and J.C. Bourgoin, J. Appl. Phys., 50, 6995 (1979). 